This item was submitted to Loughborough's Research Repository by the author.

Items in Figshare are protected by copyright, with all rights reserved, unless otherwise indicated.

\title{
Removal of submicron particles from solid surfaces using surfactants
}

PLEASE CITE THE PUBLISHED VERSION

http://dx.doi.org/10.1016/j.colcom.2015.10.001

\section{PUBLISHER}

(c) Elsevier

VERSION

VoR (Version of Record)

\section{PUBLISHER STATEMENT}

This work is made available according to the conditions of the Creative Commons Attribution-NonCommercialNoDerivatives 4.0 International (CC BY-NC-ND 4.0) licence. Full details of this licence are available at: https://creativecommons.org/licenses/by-nc-nd/4.0/

\section{LICENCE}

CC BY-NC-ND 4.0

\section{REPOSITORY RECORD}

Mahdi, Faiz M., T.E. Record, C.A. Amadi, F.O. Emmanuel, Natalia A. Ivanova, Anna Trybala, and Victor Starov. 2017. "Removal of Submicron Particles from Solid Surfaces Using Surfactants". figshare. https://hdl.handle.net/2134/25762. 
Rapid Communication

\title{
Removal of submicron particles from solid surfaces using surfactants
}

\author{
F.M. Mahdi a , T.E. Record ${ }^{\text {a }}$, C.A. Amadi ${ }^{\text {, F.O. Emmanuel }}{ }^{\text {a }, ~ N . ~ I v a n o v a ~}{ }^{\text {b }}$, A. Trybala ${ }^{\text {a }}$, V.M. Starov ${ }^{\text {a,* }}$ \\ a Department of Chemical Engineering, Loughborough University, Loughborough, Leicestershire LE11 3TU, UK \\ b Institute of Physics and Technology, Tyumen State University, Semakova 10, Tyumen 625003, Russia
}

\section{A R T I C L E I N F O}

\section{Article history:}

Received 26 August 2015

Received in revised form 6 October 2015

Accepted 13 October 2015

Available online 6 December 2015

\section{Keywords:}

Surfaces cleaning

Nanoparticles

Surfactants

Hydrophilic and hydrophobic particles and

surfaces

\begin{abstract}
A B S T R A C T
The removal of nano- or submicron particles from solid substrates is of considerable interest in a range of existing industries including cleaning of surfaces inside a spacecraft after evaporation of nanofluids. A method of nanoparticle removal using aqueous surfactant solutions is proposed. The surfactants' cleaning efficiency is investigated for all four combinations of hydrophilic (HL) and hydrophobic (HB) nanoparticles and surfaces, in order to find the most successful cleaning method in each combination. Carbon and silica nanoparticles deposited onto Teflon and glass surfaces were used. Cationic, anionic and non-ionic surfactants with a range of CMCs and HLBs were used in order to identify the best surfactant in each scenario.
\end{abstract}

(C) 2015 Elsevier B.V. This is an open access article under the CC BY-NC-ND license (http://creativecommons.org/licenses/by-nc-nd/4.0/).
The currently increasing focus on nanotechnology and the use of microstructures is beneficial to a number of industries, as well as to the ever improving quality of consumer products. However, nanoparticles have a tendency to bind to solid surfaces with incredible strength and can cause fouling to micro-structured devices [1]. This resilience is due to various intermolecular forces between the particles and the surface, such as Van der Waals, electrostatic forces and hydrogen bonding [2]. The effect of nanoparticle fouling on microstructures, however, is relatively unknown despite rising industrial interest in their uses [3].

There are a number of current methods to remove nanoparticles from solid surfaces such as those using nanobubbles [4], megasonics [5], lasers [6], aerosols [5] and chemical etching [7] among others. Although the previously mentioned techniques have shown to be effective at nanoparticle sizes as low as $10 \mathrm{~nm}$, many have notable drawbacks. Examples of this include the required use of highly specialised equipment, which demand precise optimisation to be used effectively and sensitivity to fluctuations in parameters such as temperature [5]. Many of the methods, particularly those using lasers, operate on a very small area, making the cleaning of larger surfaces significantly more difficult.

The use of suitable selection of surfactants to remove two different types of nanoparticles from solid surfaces is proposed below in order to develop an easier and reliable procedure, which has the potential to be carried out without astronauts interference inside a spacecraft.

\footnotetext{
* Corresponding author at: Department of Chemical Engineering, Loughborough University, Loughborough, LE11 3TU, UK.

E-mail address: V.M.Starov@lboro.ac.uk (V.M. Starov).
}

Below we investigate all possible scenarios with regard to the nature of the surface and particles and surfactants. The surfactants used were selected due to their range of properties, such as critical micelle concentration (CMC) and hydrophile-lipophile balance (HLB), and were used for all combinations of hydrophilic (HL) and hydrophobic (HB) nanoparticles and surfaces in order to investigate the most effective for each of four possible scenarios. Experiments of spreading or/ and evaporation of nanosuspensions inside space crafts are supposed to be undertaken in the future. However, the residual nano-particles left on the solid surface after evaporation should be removed without the interference of astronauts, that is, the cleaning method should allow a complete automatisation. The method suggested below is capable of solving the mentioned problem.

In order to have a clean glass slides to use in the experiments, the slides were left for $45 \mathrm{~min}$ in a 1:1 volume solution of concentrated sulphuric acid (>95\%) and hydrogen peroxide (35\%) known as Piranha solution. After that, the slides were left in a beaker with reverse osmosis water (RO-water) and heated to $70{ }^{\circ} \mathrm{C}$ for a further $45 \mathrm{~min}$ before being used.

As a smooth surface was required the slides chosen were Corning 2947-75 $\times 25 \mathrm{~mm}$ Micro Slides (plain), with a thickness of $1 \mathrm{~mm}$. The Teflon film was Goodfellow LS389078 PTFE Film with a thickness of $0.05 \mathrm{~mm}$. The contact angles of pure water on both substrates (clean Glass and Teflon) were found to be $5.0 \pm 1 \mathrm{deg}$. and $109.6 \pm 0.2 \mathrm{deg}$., respectively.

The hydrophilic (HL) and hydrophobic (HB) particles, which were selected for experiments were silica $(0.5-10 \mu \mathrm{m}$, approx. $80 \%$ between 1 and $5 \mu \mathrm{m}$; Sigma-Aldrich S5631) and carbon (<500 nm; SigmaAldrich 699632), respectively. Suspensions were made of each particle by adding the powders to RO-water, then agitated in an ultrasonic 
Table 1

The CMC, HLB, pH and conductivity values of the used surfactants.

\begin{tabular}{|c|c|c|c|c|c|}
\hline Type & Surfactant & $\begin{array}{l}\mathrm{CMC} \\
\mathrm{mM}\end{array}$ & $\mathrm{HLB}^{\mathrm{a}}$ & $\mathrm{pH}$ & $\begin{array}{l}\text { Cond. } \\
\mu \mathrm{s} / \mathrm{cm}\end{array}$ \\
\hline \multirow{3}{*}{ Anionic } & Sodium dodecyl sulphate (SDS) & $8.2^{\mathrm{A}}$ & 40.0 & 7 & 702 \\
\hline & $\begin{array}{l}\text { Sodium 1-octanesulfonate } \\
\text { monohydrate (1-SOS) }\end{array}$ & $155^{\mathrm{B}}$ & 41.9 & 5.5 & 8529 \\
\hline & $\begin{array}{l}\text { Sodium 1-dodecanesulfonate } \\
\text { (1-SDDS) }\end{array}$ & $7^{\mathrm{E}}$ & 9.7 & 6.3 & 446 \\
\hline \multirow{4}{*}{ Non-ionic } & Triton X-100 (T-X-100) & $0.24^{\mathrm{F}}$ & 13.5 & 6.2 & 180 \\
\hline & Tween 20 (T-20) & $0.05^{\mathrm{G}}$ & 16.7 & 5.9 & 370 \\
\hline & Novec ${ }^{\mathrm{TM}}$ FC-4430 & $0.17^{\mathrm{A}}$ & - & 6 & 18 \\
\hline & Novec $^{\mathrm{TM}}$ FC-4432 & $0.5^{\mathrm{A}}$ & - & 4.6 & 28 \\
\hline \multirow{2}{*}{ Cationic } & $\begin{array}{l}\text { Dodecyltrimethylammonium } \\
\text { bromide (DoTAB) }\end{array}$ & $11^{\mathrm{C}}$ & 12 & 6.7 & 1070 \\
\hline & $\begin{array}{l}\text { Myristyltrimethylammonium } \\
\text { bromide (MTAB) }\end{array}$ & $4^{\mathrm{D}}$ & 14 & 5.7 & 387 \\
\hline
\end{tabular}

A: From experimental data; B: [8]; C: [9]; D: Sigma-Aldrich, 2015; E: [10]; F: [11];

G: [11].

a All HLB values were calculated using the Davies method [12] bath for an hour to have a homogeneous suspension. The first half of the experiments (HB particles on $\mathrm{HB}$ substrate and $\mathrm{HB}$ particles on $\mathrm{HL}$ substrate) were conducted using the carbon suspensions and the latter half (HL particles on HL substrates and HL particles on HB substrates) using silica suspensions. The HL and HB surfaces where the particles were deposited onto were glass slides (HL) and Teflon film (HB), respectively. These materials were chosen due to the variety of industrial applications in which they are used, such as windows and containers for glass and a range of aerospace components made of Teflon. After the slides had been cleaned, as discussed above, a $5 \mu \mathrm{L}$ droplet of a suspension was deposited onto the centre of each solid substrate using a micropipette. The slides were then covered in order to protect the droplets from contamination and left for $24 \mathrm{~h}$ to dry.

Table 1 shows the chosen surfactants and their properties including critical micelle concentration (CMC), hydrophilic-lipophilic balance (HLB), pH and conductivity values (at $1 \mathrm{CMC}$ ). This selection of surfactants provided a suitable variety of CMCs and other properties required.

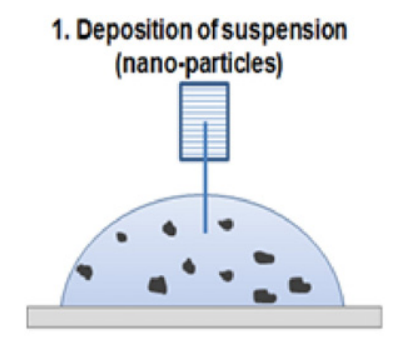

4. Deposition of surfactant

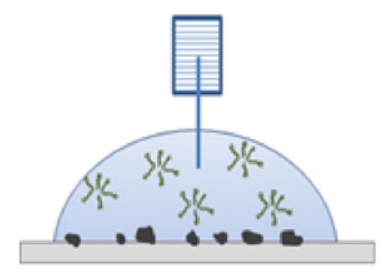

2. Drying Suspension$24 \mathrm{Hrs}$
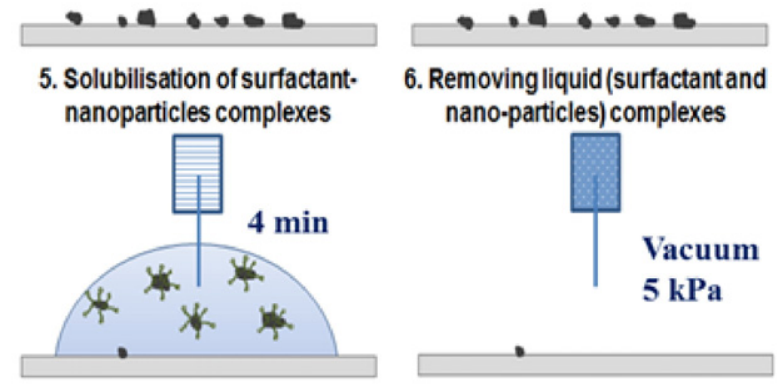

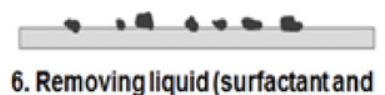

nano-particles) complexes

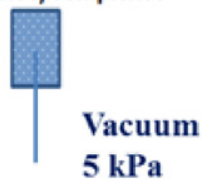

3. Surface with nano-particles

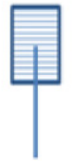

$5 \mathrm{kPa}$

a

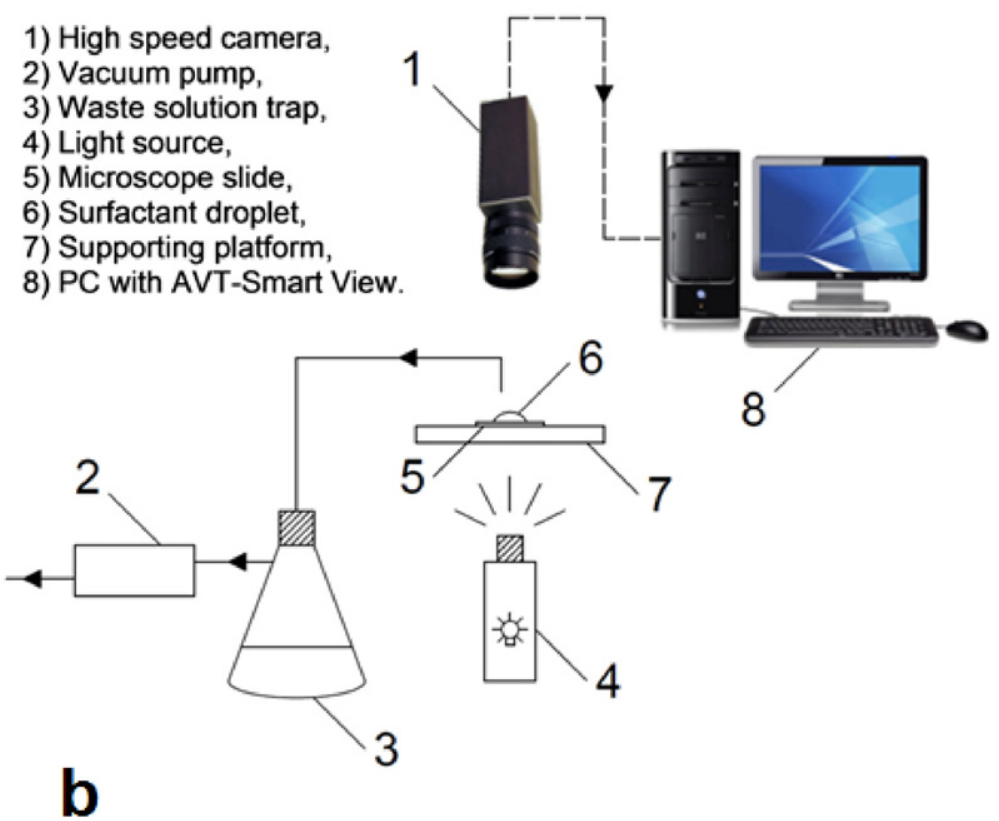

Fig. 1. a-Schematic presentation of the methodology steps; b-diagram of the experimental apparatus. 
Droplets of $5 \mu \mathrm{L}$ of each suspension with a range of concentrations for each type were deposited onto glass slides with and without Teflon film attached to the slide. The Teflon film was attached to a slide using a double sided tape. The droplets were then left for $24 \mathrm{~h}$ to evaporate, allowing for the particle to be completely deposited onto the substrate used. It has been decided that the residual particle deposits on the corresponding solid support should be visible under a microscope. The following concentrations were selected according to this requirement: $0.2 \%$ and $6 \% \mathrm{w} / \mathrm{w}$ for carbon and silica suspensions, respectively.

After that a bigger droplet $(7.5 \mu \mathrm{L})$ of surfactant solutions (secondary droplet) was deposited on the solid substrate to cover completely the residual particles on the solid substrate. Solutions for each type of surfactant were produced over a range of concentrations relative to the corresponding CMC. The concentrations chosen were $0.5,1,5,10$ and $15 \mathrm{CMC}$ for each type of surfactant.

It was necessary to select an exposure time after a deposition of the secondary droplet to make sure that the removal of residual particles is completed. It was found that $0.5 \mathrm{CMC}$ droplets of SDS has the weakest removal effect. That is droplets of $7.5 \mu \mathrm{L}$ of SDS with a concentration of 0.5 CMC were applied to each sample and left for 1, 2, 4, 10 and $15 \mathrm{~min}$. A concentration of $0.5 \mathrm{CMC}$ (being the weakest concentration) was used for these experiments as it should require the longest time to finalise the process. This meant that the selected time period would be suitable even for the worst case scenario in terms of time. The duration of secondary droplet deposition was selected as $4 \mathrm{~min}$.

The secondary droplets were then removed from the sample using the same syringe with a precision vacuum operated at $5 \mathrm{kPa}$. It was discovered previously that even as vacuum pressures as $100 \mathrm{kPa}$ was unable to remove the residual particles by itself. A pressure of $5 \mathrm{kPa}$ was therefore selected as it posed no threat of damage of the samples and provided adequate suction for the removal of the secondary droplet of surfactant.

In order to investigate the effect of the surfactant on the particles removal the slide with the dry nanoparticle placed underneath a high speed camera as shown in Fig. 1b. AVT Smart View software within a PC was used to take and analyse the droplet images. Camera settings were identical throughout.

A $7.5 \mu \mathrm{L}$ droplet of surfactant was deposited to fully cover the residual particles on the slide and left for 4 min to draw the particles into solution. The droplet was then removed from the surface using the precision vacuum and an image was taken. The schematic presentation of the methodology steps is shown in Fig. 1a. Deposition of the secondary droplet and its removal was repeated until either the slide was entirely clean (based on the naked eye observation) or until the particles remained completely unchanged after five applications of secondary droplets. For some samples which showed no change from the start, 15 applications were used in order to allow the surfactant sufficient opportunity to remove the particles.

The described above procedure was repeated for all surfactants and for all combinations of $\mathrm{HB}$ and $\mathrm{HL}$ surfaces and particles.

To investigate the cleaning efficiency of the surfactant, the slide with a residue after complete evaporation of the initial droplet was placed underneath a high speed camera $(640 \times 480,1: 1.4)$ as shown in Fig. $1 \mathrm{~b}$. The percentage of removal (cleaning) was calculated for each sample by analysing the initial area of the droplet and the final residue area covered by particles using Image J software. The final residue area is the summation of all particles, spots and cluster areas that are present in the final image. In the case of samples which were seemed clean using these camera resolution, a high resolution microscope $(0.90 \mu \mathrm{m} / \mathrm{pix})$ was used for further check and analysis any particles, spots and cluster areas. Once all images had been collected, the percentage of removal (cleaning) was calculated for each sample by analysing the initial and final residues area with ImageJ software using Eq. (1). The cleaning efficiency $(E)$ is found by subtracting the summation of the final particles area $\left(A_{r p}\right)$, the final cluster area $\left(A_{r c}\right)$ and the final spots area $\left(A_{r s}\right)$ from the initial droplet area $\left(A_{t i}\right)$. The output is divided by the initial droplet area in order to find the cleaning efficiency as a ratio of the initial droplet area.

$E=\frac{A_{t i}-\sum\left(A_{r p}, A_{r c}, \ldots A_{r s}\right)}{A_{t i}} \times 100$.

In the case of Hydrophobic Nanoparticles on a Hydrophilic Surface (HB on HL) MTAB (cationic), FC-4432 (non-ionic), 1-SDDS (anionic) and T-20 (non-ionic) are by far the most effective cleaning surfactants, with samples consistently being above $90 \%$ cleaned: the surfactants cleaning efficiency reaches peak values of 98.9, 98.0, 98.4 and 95.7\% for concentration of 5, 0.5, 10 and $5 \mathrm{CMC}$, respectively.

However, in the case of $\mathrm{HB}$ on HL, water alone turns out the best cleaning agent: close to $100 \%$ cleaning efficiency.

For Hydrophilic Nanoparticles on a Hydrophilic Surface (HL on HL) the surfactants generally followed clear relationships with increasing concentration. From Fig. 2(a, b) the non-ionic surfactants (a) show very poor cleaning efficiency, in general, less than $35 \%$ compared to anionic (60\%) and cationic surfactants (98\%).

DoTAB shows the best performance in this case attaining a max removal of $98.13 \%$ and levelling off at around 5 CMC. MTAB also displayed a significant removal, though it only achieved its peak removal of $82.93 \%$ at 10 CMC before declining. None of the other surfactants attained removal values higher than 65\%, as seen in Fig. 2(a, b). Furthermore, from the same figure, it can be seen that water alone is extremely poor at removing HL nanoparticles, with a removal efficiency of $1.14 \%$.

Hydrophobic Nanoparticles on a Hydrophobic Surface (HB on HB) scenario all types of surfactants used in this research performed significantly worse than in all other scenarios, with the highest percentage of cleaning being 1 -SDDS at a peak of 53\%. Similarly to HB on HL scenario, an anionic surfactant showed a better effective cleaning. Using only
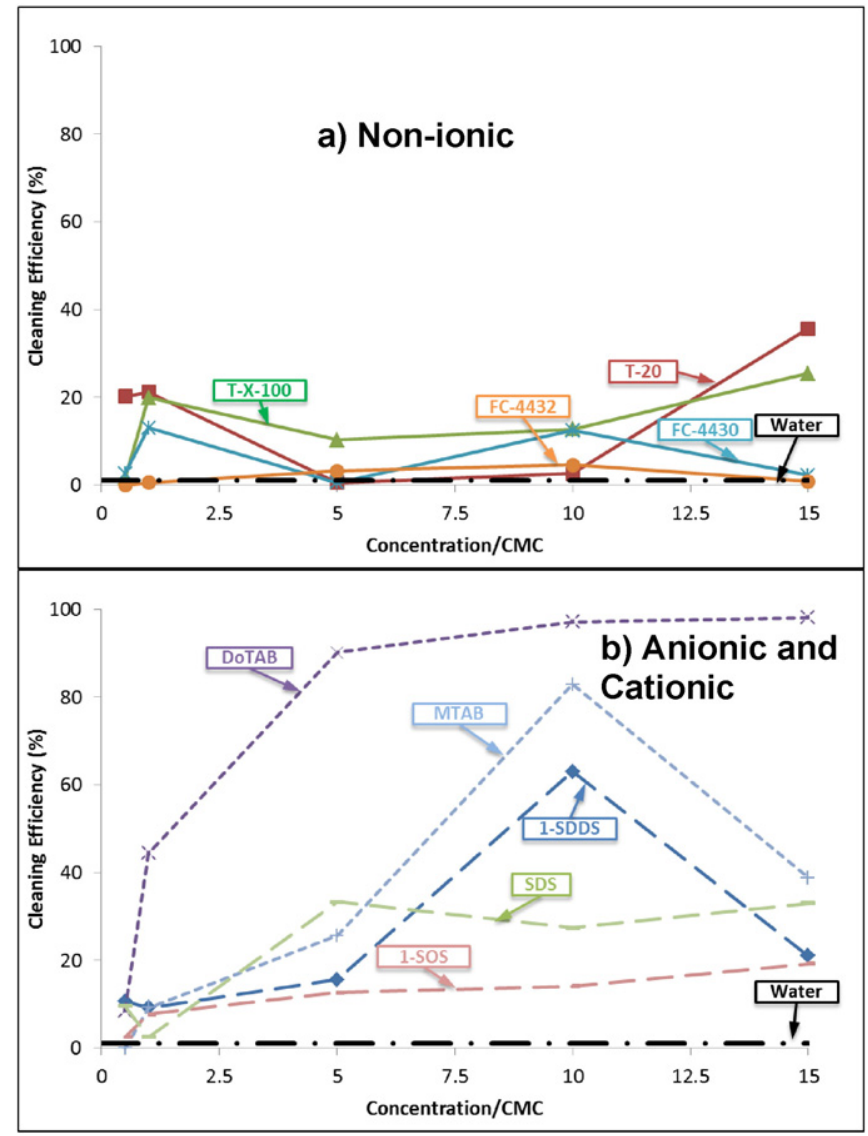

Fig. 2. Variation of the percentage of nanoparticle removal with respect to surfactant concentration Hydrophilic Particles (Silica) on Hydrophilic Surface (Glass). 
Table 2

The average initial particle deposition area and standard deviation for each scenario.

\begin{tabular}{lll}
\hline Scenario & Average initial area, $\mathrm{mm}^{2}$ & Standard deviation \\
\hline HB on HL & 38.60 & 3.62 \\
HL on HL & 26.01 & 1.42 \\
HB on HB & 4.23 & 0.60 \\
HL on HB & 2.28 & 0.36
\end{tabular}

water obtained a percentage of removal of $3.8 \%$. This scenario turns out to be the hardest for removal of residue particles and a different method is required.

Next scenario investigated was Hydrophilic Nanoparticles on a Hydrophobic Surface (HL on HB). The degree of cleaning in this scenario (HL on $\mathrm{HB}$ ) was by far the highest, with most surfactants achieving removal values of almost $100 \%$. In this case all surfactants were equally effective and, when compared to water, show no benefit in using a surfactant to clean the surface at all. In this case, the cleaning is so easy that the use of water alone would be the most effective in terms of results and cost.

In order to observe and compare the degree of wetting by the suspensions used the initial areas and standard deviations of the deposits once fully dry were recorded and presented in Table 2 . There is a clear difference between the HL and HB surfaces with regard to deposited size: the initial areas for HL surfaces are much larger than those of HB surfaces. This is due to the use of aqueous surfactant solutions, which wet a HL surface more effectively. It should be noted that the HB particle deposits in each case are slightly larger than those of the HL particles.

For each scenario except for $\mathrm{HB}$ on HL, the standard deviation is low (from 0.4 to 3.6) with regard to the average values. During the experiments, it became apparent that the way that the carbon nanoparticles arranged themselves onto the surface was very different.

A method of nanoparticle removal using aqueous surfactant solutions is proposed. The surfactants' cleaning efficiency is investigated for all four combinations of hydrophilic (HL) and hydrophobic (HB) nanoparticles and surfaces, in order to find the most successful cleaning method in each combination. Carbon and silica nanoparticles deposited onto Teflon and glass surfaces were used. Cationic, anionic and nonionic surfactants with a range of CMCs were used in order to identify the best surfactant in each scenario. It was found that for the HB on HL and HL on HB scenarios, water is more effective than all surfactants in terms of cleaning efficiency. For the HL on HL scenario, it was discovered that cationic DoTAB surfactants were optimal as cleaning agents. However, the HB on HB scenario proved resilient to water and each surfactant used and will require further investigation.

This work has clearly demonstrated that the use of surfactants for nanoparticle removal is viable for a range of scenarios. It has also been shown that for certain scenarios, surfactants can be used to achieve significantly high cleaning rates than using water alone, solidifying the technique as a simple, effective and cost efficient method.

\author{
Abbreviations \\ HL hydrophilic \\ HB hydrophobic \\ CMC critical micelle concentration \\ HLB hydrophilic-lipophilic balance
}

\section{Acknowledgements}

Authors are grateful to the Royal Society (Grant no. 2014 Russia (RFBR) Costshare), UK and the Russian Foundation for Basic Research (Grant no. 14-01-92602 KO_a); MAP EVAPORATION project, European Space Agency; Marie Curie CoWet project, EU; Procter \& Gamble, USA and COST-MP1106, EU for supporting this research. N. Ivanova acknowledges financial support from the Ministry of Education and Science of the Russian Federation, the programme of The Organization of Scientific Research (Grant no. 3-14).

\section{References}

[1] N. Kockmann, M. Engler, P. Woias, Particulate fouling in micro-structured devices. ECI symposium series, in: H. Müller-Steinhagen, M.R. Malayeri, A.P. Watkinson (Eds.), Volume RP2: Proceedings of 6th International Conference on Heat Exchanger Fouling and Cleaning -Challenges and Opportunities, RP2, Engineering Conferences International, Kloster Irsee, Germany, 2005.

[2] D.S. Rimai, D.J. Quesnel, Fundamentals of Particle Adhesion, Global Press, Polymer Surfaces and Interfaces Series, 2001.

[3] M. Schoenitz, J.H. Finke, S. Melzig, A. Hohlen, N. Warmeling, C. Müller-Goymann, W. Augustin, S. Scholl, Fouling in a Micro Heat Exchanger During Continuous Crystallization of Solid Lipid Nanoparticles, International Conference on Heat Exchanger Fouling and Cleaning, Budapest, Hungary, 2013.

[4] S. Yang, A. Duisterwinkel, Removal of nanoparticles from plain and patterned surfaces using nanobubbles, Langmuir 27 (18) (2011) 11430-11435.

[5] I. Kim, K.S. Hwang, J.W. Lee, Removal of 10-nm contaminant particles from Si wafers using $\mathrm{CO}_{2}$ bullet particles, Nanoscale Res. Lett. 7 (2012).

[6] J.K. Park, J.W. Yoon, S.H. Cho, Removal of nanoparticles from a silicon wafer using plasma shockwaves excited with a femtosecond laser, Appl. Surf. Sci. 258 (17) (2012) 6379-6383 6/15.

[7] W. Kern, Handbook of Semiconductor Wafer Cleaning Technology: Science, Technology and Applications, Noyes Publications, Park Ridge, NJ, USA, 1993.

[8] P. Mukerjee, K.J. Mysels, Critical micelle concentrations of aqueous surfactant systems, U. S. Natl. Stand. Ref. Data Syst. 36 (1971).

[9] C.E. Lin, T.Z. Wang, T.C. Chiu, C.C. Hsueh, Determination of the critical micelle concentration of cationic surfactants by capillary electrophoresis, J. High Resolut. Chromatogr. 22 (5) (1999) 265-270.

[10] F. Hernainz, M. Calero, G. Blazquez, A. Caro, Surface tension for aqueous solutions of sodium 1-dodecanesulfonate, J. Chem. Eng. Data 51 (2006) 1216-1219.

[11] S.K. Hait, S.P. Moulik, Determination of critical micelle concentration (CMC) of nonionic surfactants by donor-acceptor interaction with iodine and correlation of CMC with hydrophile-lipophile balance and other parameters of the surfactants, J. Surfactant Deterg. 4 (3) (2001) 303-309.

[12] J.T. Davies, A quantitative kinetic theory of emulsion type. physical chemistry of the emulsifying agent, 2nd International Congress of Surface Activity. London, 1957. 